\title{
COMPARISON OF 0.1\% TOPICAL ADAPALENIN GEL VERSUS 0.05\% ISOTRETINOIN GEL IN PATIENTS WITH MILD TO MODERATE ACNE VULGARIS
}

\author{
DR. SADAF IQBAL, MBBS \\ Department of Obstetrics and Gynecology, \\ Sheikh Zayed Medical College, Rahim Yar Khan, Pakistan. \\ DR. AMBER IRFAN, MBBS \\ Department of Obstetrics and Gynecology, \\ Sheikh Zayed Medical College, Rahim Yar Khan, Pakistan.
}

DR. UROOJ IRFAN, MBBS

Department of Obstetrics and Gynecology, Nishtar Medical University, Multan, Pakistan.

\begin{abstract}
;
Background; Acne Vulgaris leads to significant increase in psychological issues among patients and has negative impact on quality of life and their productivity. Objective; The objective of this study is to compare efficacy of $0.1 \%$ topical adapalenin gel versus $0.05 \%$ isotretinoin gel in patients with mild to moderate acne vulgaris. Material and Methods; Group A, having 30 patients, was treated with $0.1 \%$ adapalene gel in the morning and evening (twice a day) while Group B, also having 30 patients treated with $0.05 \%$ isotretinoin gel twice a day for 6 weeks. The patients were followed weekly till 6 weeks from the beginning of therapy to observe efficacy. Results; Of these 60 study cases, $18(30.0 \%)$ were male patients while $42(60.0 \%)$ were female patients. Mean age of our study cases was $20.43 \pm 3.37$ years. Mean body mass index of our study cases was $25.12 \pm 2.21 \mathrm{~kg} / \mathrm{m}^{2}$ and obesity was present in $13(21.7 \%)$ of our study cases. Of these 60 study cases, $30(50 \%)$ had mild acne and $30(50 \%)$ moderate acne Mean disease duration was $4.52 \pm 2.68$ months and $54(90.0 \%)$ had duration of illness up to 6 months. Of these 60 study cases, $17(28.3 \%)$ were illiterate and $43(71.7 \%)$ were literate. Efficacy was noted in $35(58.3 \%)$, in group A efficacy was noted to be $23(76.7 \%)$ and efficacy in group B was noted be 12 $(40.0 \%)$. ( $\mathrm{P}=0.008)$. Conclusion; Adapalene gel was found to be more effective, safe and reliable therapy for the treatment of mild to moderate acne as this therapy was significantly more efficacious as compared with $0.05 \%$ isotretinoin gel. Our study results support the use of Adapalene gel for the treatment of mild to moderate acne as it provides desired outcomes which leads to improvement in quality of life these patients and also their productivity. This will also provide psychological relief to the patients having significant burden of psychological stress.
\end{abstract}

Keywords; Acne vulgaris, Adapalene, Isotretinoin gel, efficacy.

DOI: $10.7176 / \mathrm{JMPB} / 61-05$

Publication date: November $30^{\text {th }} 2019$ 


\section{INTRODUCTION;}

Acne is a chronic inflammatory disease of pilosebaceous units. It is characterized by seborrhea, the formation of open and closed comedones, eryhtematous papules and pustules and in more severe cases nodules, deep pustules and pseudocyst. It is a common dermatologic disease that is usually managed by application of topical preparations, systemic medications, or a combination of the two ${ }^{1-4}$ And is commonest skin disease, mainly in young ages, which dermatologists have to encounter in their daily routine ${ }^{5}$. Antibiotics play a pivotal role in treatment. However, the emergence of new resistant strains or cross-resistance, development of various side effects, and poor tolerability are factors that sometimes limit their usefulness ${ }^{6,7}$.

Acne vulgaris is a common condition extremely prevalent among teenagers and young adults under the age of 24 years. Nearly $85 \%$ of adolescents in this age group experience some degree of acne. Acne lasts for several years and thus may significantly influence in many ways the lives of those affected. For many teens, the disease could create cosmetic, physical, and psychological scarring fueling anxiety, depression, and other emotional trauma that threaten their quality of life ${ }^{8-11}$. Therefore, early and effective treatment is needed to save these patients from all the possible complications. Successful treatment of acne is significantly affected by the level of knowledge of the patients ${ }^{12}$

Acne is usually diagnosed by the patient. The physician needs to determine if the condition is noninflammatory (open and closed comedones), inflammatory (papules or pustules) or a mixture of both (the most common situation). Many therapeutic options exist for treating acne including topical benzoyl peroxide, topical and oral antibiotics, topical and oral retinoids and oral contraceptives. Consensus guidelines advocate that the use of topical retinoids are primary treatment for most forms of acne treatment. However, all topical retinoids may be irritating which contribute to their underutilization. Topical adapalene has the advantage of causing less irritation and is more stable molecule than tretinoin ${ }^{13}$. A study conducted by Khan et al ${ }^{14}$ reported efficacy with Adapalene was $84.2 \%$ while it was $39.6 \%$ with tretinoin group.

This study was designed to document the efficacy of $0.1 \%$ topical adapalene and $0.05 \%$ tretinoin in the treatment of acne, as there is no such study done in our population previously but prevalence of acne is high in our population. Once the more effective treatment is documented in our population, the results will help to treat these patients more effectively which will relieve these patients from psychological and social problems which will improve quality of life as well as productivity of these young patients.

\section{MATERIAL AND METHODS;}

Total 60 patients with mild to moderate acne of either sex aged $18-40$ years of age having duration more than 3 months were included in our study. Study was conducted in the OPD of Department of Medicine, Sheikh Zayed Medical College, Rahim Yar Khan. Patients taking anti-acne treatment within one month, having hirsutism, menstrual dysfunction, taking oral contraceptives, diabetes and hypertension were excluded from our study. Patients were randomly allocated in to two groups by lottery method. Group A, having 30 patients, was treated with $0.1 \%$ adapalene gel (about half of pea size amount for full face) in the morning and evening (twice a day) while Group B, also having 30 patients treated with $0.05 \%$ isotretinoin gel twice a day (about half of pea size amount for full face in morning and evening) for 6 weeks in patients with mild to moderate acne. The patients were followed weekly till 6 weeks from the beginning of therapy to observe efficacy. All the data was entered and analyzed using SPSS-20. Mean and standard deviation for the age, BMI of patient and duration of disease was calculated. Frequencies and percentage were calculated for the categorical variables like gender, disease severity (mild/moderate), age groups, efficacy (Present/Absent) and Obesity (Obese/Non-obese), family income, educational status. Efficacy was compared in both groups and chi-square test was applied for comparison of efficacy at level of significance of 0.05 . 


\section{RESULTS;}

Our study comprised of a total of 60 patients meeting inclusion criteria of our study. Of these 60 study cases, $18(30.0 \%)$ were male patients while $42(60.0 \%)$ were female patients. Mean age of our study cases was $20.43 \pm 3.37$ years (with minimum age of our study cases was 18 years while maximum age was 32 years). Mean age of the male patients was noted to be $19.28 \pm 3.37$ years while that female patients was $20.93 \pm 3.29$ years $(\mathrm{p}=0.083)$. Our study results have indicated that majority of our study cases i.e. $53(88.3 \%)$ were aged up to 30 years. Of these 60 study cases, $25(41.7 \%)$ belonged to rural areas and $35(58.3 \%)$ belonged to urban areas. Monthly family income up Rs. 30000 was noted in $19(31.7 \%)$ and more than 30000 rupees was noted in 41 $(68.3 \%)$. Mean body mass index of our study cases was $25.12 \pm 2.21 \mathrm{~kg} / \mathrm{m}^{2}$ and obesity was present in $13(21.7$ $\%$ ) of our study cases. Of these 60 study cases, $30(50 \%)$ had mild acne and $30(50 \%)$ moderate acne. Mean disease duration was $4.52 \pm 2.68$ months and $54(90.0 \%)$ had duration of illness up to 6 months. Of these 60 study cases, $17(28.3 \%)$ were illiterate and $43(71.7 \%)$ were literate. Efficacy was noted in $35(58.3 \%)$, in group A efficacy was noted to be $23(76.7 \%)$ and efficacy in group B was noted be $12(40.0 \%)(\mathrm{P}=0.008)$.

Table No. 9 Distribution of study cases by Efficacy.

\begin{tabular}{|c|c|c|c|c|}
\hline \multirow{2}{*}{$\begin{array}{c}\text { Efficacy } \\
(\mathrm{n}=60)\end{array}$} & \multicolumn{2}{|c|}{ Group A } & \multicolumn{2}{c|}{ Group B } \\
\cline { 2 - 5 } & Frequency & Percentage & Frequency & Percentage \\
\hline $\begin{array}{c}\text { Yes } \\
\mathrm{n}=35 \\
(58.3 \%)\end{array}$ & 23 & 76.7 & 12 & 40.0 \\
\hline $\begin{array}{c}\text { No } \\
\mathrm{n}=25\end{array}$ & 07 & 23.3 & 18 & 60.0 \\
$(41.7 \%)$ & & & & \\
\hline Total & $\mathbf{3 0}$ & $\mathbf{1 0 0}$ & $\mathbf{3 0}$ & $\mathbf{1 0 0}$ \\
\hline
\end{tabular}

$* \mathrm{p}=0.008$, which is statistically significant.

\section{DISCUSSION;}

Acne is one of the most common disorders treated by dermatologists and other health care providers. According to the Global Burden of Disease (GBD) study, acne vulgaris affects $\sim 85 \%$ of young adults aged $12-25$ years. The choice of therapy should be principally based on the type of lesion and the severity of the acne, but psychosocial disability relating to the disease and the presence of scarring may also influence the approach to treatment.

Our study comprised of a total of 60 patients meeting inclusion criteria of our study. Of these 60 study cases, 18 (30.0\%) were male patients while 42 (60.0\%) were female patients. A study conducted by Batool et al ${ }^{15}$ from Rahim Yar Khan also documented $87 \%$ female gender predominance which is in compliance with our study results. A study conducted by Ghafoor et al ${ }^{16}$ from Karak has also documented 0.82:1.11 female gender predominance which is in compliance with our study results. Shaukat et al ${ }^{17}$ from Lahore has also reported $80 \%$ female gender predominance in acne patients which is close to our study results. A study conducted by Sohail et al ${ }^{18}$ from Karachi has also reported $65 \%$ female gender predominance which is close to our study results. An Indian study conducted by Hazarika et al ${ }^{20}$ has also documented $56 \%$ female gender predominance which is close to our study results. However another study from India conducted by Gupta et al ${ }^{21}$ has reported $63 \%$ male gender predominance which is different from our study results.

Mean age of our study cases was $20.43 \pm 3.37$ years (with minimum age of our study cases was 18 years while maximum age was 32 years). Mean age of the male patients was noted to be $19.28 \pm 3.37$ years while that female patients was $20.93 \pm 3.29$ years $(\mathrm{p}=0.083)$. Our study results have indicated that majority of our study cases i.e. $53(88.3 \%)$ were aged up to 30 years. A study conducted by Batool et al ${ }^{15}$ from Rahim Yar Khan also documented $18.8 \pm 2.7$ years mean age of the acne patients which is close to our study results. A study conducted by Ghafoor et al ${ }^{16}$ from Karak has also documented $18.45 \pm 2.91$ years mean age which is close to our study results. Shaukat et al ${ }^{17}$ from Lahore has also reported $20.45 \pm 3.27$ years mean age which is close to our study results. A study conducted by Sohail et al ${ }^{18}$ from Karachi has also reported 21.4 years mean age which is close to 
our study results. another study from India conducted by Gupta et al ${ }^{21}$ has reported $22.49 \pm 5.38$ years mean age which is close to our study results.

Of these 60 study cases, 25 (41.7\%) belonged to rural areas and $35(58.3 \%)$ belonged to urban areas. Monthly family income up Rs. 30000 was noted in 19 (31.7\%) and more than 30000 rupees was noted in 41 $(68.3 \%)$. A study conducted by Batool et al ${ }^{15}$ from Rahim Yar Khan also documented $30.4 \%$ patients of acne from rural areas which is in compliance with our study results.

Mean body mass index of our study cases was $25.12 \pm 2.21 \mathrm{~kg} / \mathrm{m}^{2}$ and obesity was present in $13(21.7 \%)$ of our study cases. Of these 60 study cases, $30(50 \%)$ had mild acne and $30(50 \%)$ moderate acne. Mean disease duration was $4.52 \pm 2.68$ months and $54(90.0 \%)$ had duration of illness up to 6 months. Of these 60 study cases, $17(28.3 \%)$ were illiterate and $43(71.7 \%)$ were literate. A study conducted by Batool et al ${ }^{15}$ from Rahim Yar Khan also reported similar results.

Efficacy was noted in 35 (58.3\%), in group A efficacy was noted to be $23(76.7 \%)$ and efficacy in group B was noted be $12(40.0 \%)(\mathrm{P}=0.008)$. A study conducted by Khan et al ${ }^{14}$ reported efficacy with Adapalene was $84.2 \%$ while it was $39.6 \%$ with tretinoin group. These findings are close to our study results. Another study conducted by Loannides et al $^{22}$ in Greece also reported Adapalene being more effective than tretinoin group which is similar to that of our study results.

\section{CONCLUSION;}

Adapalene gel was found to be more effective, safe and reliable therapy for the treatment of mild to moderate acne as this therapy was significantly more efficacious as compared with $0.05 \%$ isotretinoin gel. Our study results support the use of Adapalene gel for the treatment of mild to moderate acne as it provides desired outcomes which leads to improvement in quality of life these patients and also their productivity. This will also provide psychological relief to our patients as it is associated with significant burden of psychological stress.

\section{REFERENCES}

1. Hsu P, Litman GI, Brodell RT. Overview of the treatment of acne vulgaris with topical retinoids. Postgrad Med. 2011;123:153-61.

2. Kraft J, Freiman A. Management of acne. CMAJ. 2011;183:430-5.

3. Smith EV, Grindlay DJ, Williams HC. What's new in acne.? An analysis of systematic reviews published in 2009-2010. Clin Exp Dermatol. 2011;36:119-22.

4. Faghihi G, Rakhshanpour M, Abtahi-Naeini B, Nilforoushzadeh MA. The efficacy of 5\% dapsone gel plus oral isotretinoin versus oral isotretinoin alone in acne vulgaris: a randomized double-blind study. Adv Biomed Res. 2014;3:177. doi: 10.4103/2277-9175.139413.

5. Simonart T. Newer approaches to the treatment of acne vulgaris. Am J Clin Dermatol. 2012;13(6):35764.

6. Ingram JR, Grindlay DJ, Williams HC. Management of acne vulgaris: an evidence-based update. Clin Exp Dermatol. 2010;35:351-4.

7. Canavan $\mathrm{TN}^{1}$, Chen $\mathrm{E}^{1}$, Elewski $\mathrm{BE}^{2}$. Optimizing non-antibiotic treatments for patients with acne: a review. Dermatol Ther (Heidelb). 2016 Dec;6(4):555-578.

8. Cao $\mathrm{H}^{1}$, Yang G, Wang Y, Liu JP, Smith CA, Luo H, et al. Complementary therapies for acne vulgaris. Cochrane Database Syst Rev. 2015 Jan 19;1:CD009436. doi: 10.1002/14651858.CD009436.pub2.

9. Bez Y, Yesilova Y, Ari M, Kaya MC, Alpak G, Bulut M. Predictive value of obsessive compulsive symptoms involving the skin on quality of life in patients with acne vulgaris. Acta Derm Venereol. 2013;93:679-83.

10. Timms RM. Moderate acne as a potential barrier to social relationships: Myth or reality? Psychol Health Med. 2013;18:310-20.

11. Gupta MA, Gupta AK. Evaluation of cutaneous body image dissatisfaction in the dermatology patient. Clin Dermatol. 2013;31:72-9.

12. Magin P. Appearance-related bullying and skin disorders. Clin Dermatol. 2013;31:66-71 
13. Al-Natour $\mathrm{SH}^{1}$. Acne vulgaris: Perceptions and beliefs of Saudi adolescent males. J Family Community Med. 2017;24(1):34-43.

14. Khan M, Khan NU, Anwar MI, Noor SM. A comparison of efficacy of topical adapalene gel $0.1 \%$ with tretinoin gel 0.025 \% in mild acne vulgaris. J Pak Assoc Dermatol. 2017;27(1):37-41

15. Batool S, Mustafa G, Hanif M, Mahmood N, Sadia F, Hassan M. Perception of acne patients regarding its pathogenesis and treatment. J Sheikh Zayed Med Coll. 2010;1(2):60-4.

16. Ullah G, Noor SM, Bhatti Z, Ahmad M, Bangash AR. Comparison of oral azithromycin with oral doxycycline in the treatment of acne vulgaris. J Ayub Med Coll Abottabad. 2014;26(1):64-7.

17. Shaukat S, Aman S, Hussain I, Kazmi AH. The effect of oral doxycycline and topical 5\% benzoyl peroxide on quality of life in patients with mild to moderate acne vulgaris. J Pak Assoc Derma. 2013;23(2):173-9.

18. Ahmed S, Ahmed I. Frequency and magnitude of anxiety and depression among acne patients: a study of 100 cases J Liaquat Uni Med Health Sci. 2007;6(1):25-9.

19. Naeem, Akram B, Luqman L. Acne vulgaris; psychosocial stressors in patients Professional Med J. 2013;20(3):403-8.

20. Hazarika N, Archana M. The Psychosocial impact of acne vulgaris. Indian J Dermatol. 2016;61(5):51520.

21. Gupta A, Sharma YK, Dash KN, Chaudhari ND, Jethani S. Quality of life in acne vulgaris: Relationship to clinical severity and demographic data. Indian J Dermatol Venereol Leprol. 2016;82:292-7.

22. Ioannides $\mathrm{D}^{1}$, Rigopoulos $\mathrm{D}$, Katsambas $\mathrm{A}$. Topical adapalene gel $0.1 \%$ vs. isotretinoin gel $0.05 \%$ in the treatment of acne vulgaris: a randomized open-label clinical trial. Br J Dermatol. 2002 Sep;147(3):5237. 